\title{
PANORAMA BRASILEIRO DA PESQUISA CIENTÍFICA E NA ÁREA DE ENFERMAGEM PEDIÁTRICA
}

\section{BRAZILIAN PANORAMA OF SCIENTIFIC RESEARCH AND PEDIATRICS NURSING AREA}

\section{PANORAMA BRASILEÑO DE LA INVESTIGACIÓN CIENTÍFICA Y DEL ÁREA DE ENFERMERÍA PEDIÁTRICA}

\section{Mariana Firmino Daré ${ }^{1}$}

Como citar esse artigo: Daré MF. Panorama brasileiro da pesquisa científica e na área de enfermagem pediátrica. Rev Enferm Atenção Saúde [Internet]. 2021 [acesso em ];10(2):e202124. doi:10.18554/reas.v10i2.5851

Com as recentes mudanças sociais, políticas, econômicas e sanitárias que estão ocorrendo no Brasil, a discussão acerca da pesquisa científica e os investimentos financeiros necessários para a manutenção ou incremento desse setor tem ganhado destaque. Isso se intensifica diante de um cenário pandêmico, em que se torna extremamente importante para a contenção da COVID-19 medidas rápidas e altamente eficazes.

A partir daí, abre-se uma infinidade de temas a serem estudados sob os mais diferentes aspectos metodológicos, como por exemplo, ensaios clínicos para desenvolvimento de vacinas, estudos observacionais e de intervenção sobre hábitos de higiene e lavagem das mãos, entre outros.

No entanto, essa discussão não é recente e tão pouco se limita ao cenário pandêmico. Nesse sentido, a proposta é apresentar aqui alguns indicadores de posicionamento da pesquisa em enfermagem pediátrica no Brasil nos últimos anos, para refletimos acerca dos caminhos percorridos e das possibilidades de avanços em um breve futuro.

Segundo o SCImago Journal \& Country Rank, em 2010, o Brasil em todas as áreas do conhecimento ocupava a $13^{a}$ posição na classificação realizada pelo número de documentos publicados. Quando o critério de classificação da produção científica é pelo índice H (índice utilizado para quantificar a produção e seu impacto pelo número de citações), essa posição cai para $23^{\mathrm{a}}$. Ambas as posições se mantiveram quando comparadas 10 anos após, ou seja, em 2020 nos mantivemos na $13^{\mathrm{a}}$ posição em número de documentos e na $23^{\mathrm{a}}$ posição de acordo com o índice $\mathrm{H}$.

\footnotetext{
1 Enfermeira. Doutora em Ciências. Coordenadora de Estudos da Fundação da Faculdade de Medicina da Universidade de São Paulo (FFM-USP) no Instituto do Câncer do Estado de São Paulo (ICESP). ORCID: https://orcid.org/0000-0002-1782-559X_Lattes: http://lattes.cnpq.br/6055131511377373
} 
Para os mesmos dados classificados na área da enfermagem, observa-se que o Brasil ocupava a $8^{\mathrm{a}}$ posição na classificação realizada pelo número de documentos publicados em 2010. Já quando o critério de classificação da produção científica é pelo índice H, essa posição cai para $22^{\mathrm{a}}$. Para o ano de 2020, o Brasil subiu duas posições com relação ao número de documentos publicados, ocupando o $6^{\circ}$ lugar. No entanto, quando se compara após 10 anos, manteve-se na $22^{\mathrm{a}}$ posição de acordo com o índice $\mathrm{H}$.

Esses dados remetem a expressividade da pesquisa em enfermagem no cenário mundial quando observado o posicionamento do Brasil no ranking mundial pelo número de documentos, ou seja, no posicionamento da enfermagem $\left(6^{\circ}\right)$, o Brasil está em lugar de maior destaque quando comparado ao lugar ocupado por todas as áreas $\left(13^{\circ}\right)$.

Já na subárea da enfermagem pediátrica, observa-se que o Brasil ocupava a $17^{a}$ posição na classificação realizada pelo número de documentos publicados em 2010. Quando o critério de classificação da produção científica é pelo índice $\mathrm{H}$, essa posição cai para $27^{\mathrm{a}}$. Para o ano de 2020, o Brasil subiu duas posições em relação ao número de documentos publicados, ocupando o $15^{\circ}$ lugar. No entanto, quando comparada 10 anos após, apresentou decréscimo de uma posição, ocupando o $28^{\circ}$ lugar de acordo com o índice H. Sendo assim, a enfermagem pediátrica enquanto uma subárea da enfermagem precisa de maior potencial produtivo, incrementando o número de produções científicas enquanto especialidade. Ressalta-se que Castral, Daré e Scochi (2014) levantaram que no triênio 2010/2012 foram defendidas 343 teses ou dissertações com a temática de enfermagem pediátrica, no entanto, nesse mesmo triênio, no SCImago, aparecem apenas 12 documentos indexados.

Além disso, é urgente o investimento na qualificação da pesquisa em enfermagem, para que os documentos indexados alcancem maior impacto e ganhem maior expressividade no cenário mundial elevando as posições na classificação pelo índice H. É preciso que a área enfermagem e a subárea da enfermagem pediátrica avancem com pesquisas mais robustas, publique seus resultados em periódicos de maior impacto e que os periódicos específicos ganhem notoriedade no cenário internacional.

Por isso, faz-se necessário refletirmos sobre as práticas atuais da pesquisa em enfermagem e unir forças em prol de avançarmos para conseguirmos expor o verdadeiro potencial dessa profissão, considerando o momento oportuno de apoio social, frente aos desafios impostos pela pandemia e a reestruturação da ciência exigida. 


\section{REFERÊNCIAS}

1 Castral TC, Daré MD, Scochi CGS. Research priorities in neonatal and pediatric nursing. Rev Eletrônica Enferm. [Internet]. 2014 [citado em 10 set 2021]; 16(1):15-7. Disponível em: https://revistas.ufg.br/index.php/fen/article/view/29266. doi:

http://dx.doi.org/10.5216/ree.v16i1.29266

2 Scimago Institutions Rankings [Internet]. In: ScimagoJR. 2020. Disponível em: https://www.scimagojr.com/countryrank.php.

RECEBIDO: 10/09/2021

APROVADO: $10 / 09 / 2021$

PUBLICADO: 09/2021 